\title{
Psychiatric aspects of methylmercury poisoning
}

\author{
H. I. MAGHAZAJI
}

From the Department of Medicine, Medical College, Baghdad University, Baghdad, Iraq

SYNOPSIS Forty-three patients with methylmercury poisoning were studied $; 74.4 \%$ showed some degree of depression. Their blood levels of mercury were higher than the average values for the whole group, and considerably higher than the blood levels of the non-depressed patients. Irritability was observed in $44.2 \%$ of the patients, all except one of the 19 being under 30 years of age. There was general improvement in the mental states of the patients who were hospitalized. Mercury binding compounds did not seem to have a significant effect in enhancing recovery from the depressive state. The possibility of there being two distinct syndromes, due to organic and inorganic mercury poisoning, is discussed.

During the early months of 1972 , cases of mercury poisoning were reported among farming communities in various parts of Iraq. This was caused by ingestion of grain treated with methylmercuric fungicide. There were 6,530 cases admitted to hospitals throughout the country and 450 hospital deaths attributed to mercury poisoning were reported (Bakir et al., 1973). This was the most devastating outbreak of mercury poisoning to be recorded. This study concerns the psychiatric manifestations exhibited by the poisoned patients.

\section{METHODS}

Patients admitted to medical, neurological, and paediatric wards in hospitals in Baghdad were studied. Some of their relatives who were exposed to the poison and showed minor physical signs that did not warrant hospitalization were also included. Thirty-six patients and seven relatives were studied: 21 males ranging in age from 6 to 70 years, and 22 females from 2 to 70 years. All were agricultural workers or their dependants, and all came from the central regions of Iraq. The patients were examined clinically and their mental state assessed fully. All the interviews were conducted by the author and the help of an informant was always sought in obtaining the history and in evaluating the pre-morbid personality. The mental state was studied on two or three occasions at weekly intervals.

Patients with clouded consciousness, in coma, or

I Address for correspondence: Medical City, Neuropsychiatric Unit, Sixth Floor, Baghdad, Iraq. exhibiting severe cortical damage were not included because their mental state indicated marked brain injury common to numerous clinical syndromes with of organic involvement of the central nervous system The absence of clear consciousness was the onl $\mathbb{R}$ criterion for exemption from the study.

Blood samples were taken for estimation of mer cury levels, both organic and inorganic. The initia interviews with the patients were carried out during their first week in hospital, within a few days of taking the first blood sample. In the following paragraphs reference is made to first-blood-sample results only. Samples were examined in 36 of the 43 patients $(83 \cdot 7 \%)$.

The blood samples were analysed by gas chromatography and results expressed in nanogrammes per millilitre of blood (Bakir et al., 1973).

\section{RESULTS}

The main cause of poisoning was ingestion of home-made bread prepared from seed wheat treated with methylmercuric fungicide. In some instances both wheat and barley were used. The duration of consumption varied from a few weeks up to three months. The quantity consumed also varied, from one to six loaves daily, and each loaf weighing about $220 \mathrm{~g}$.

Symptoms appeared insidiously after a period of two to six weeks. Subjective complaints of O headache, various aches and pains, and dizziness $N$ were common. The main features consisted of $N$ neurological dysfunction in the form of ataxia, 
dysarthria, paraesthesiae, weakness, visual and hearing defects. This is consistent with findings of other investigators in this field (Eye, 1971b).

In three patients $(7 \%)$ the presenting complaints were suggestive of psychiatric disturbances. A female aged 14 years presented with a 'strange' feeling in the stomach, a male of 35 years with tremulousness and insomnia, and a 55 year old female with intense fear of dying and palpitations.

MERCURY LEVELS The total blood levels of mercury ranged between 320 and $4260 \mathrm{ng} / \mathrm{ml}$, with an average of $2,118 \mathrm{ng} / \mathrm{ml}$. The inorganic mercury blood levels were between 15 and 380 $\mathrm{ng} / \mathrm{ml}$ and with an average of $146 \mathrm{ng} / \mathrm{ml}$.

DEPRESSION Thirty-two $(74.4 \%)$ of the 43 patients were consistently depressed. Clinically, depressive symptoms were mild to moderate in degree, and constituted a feeling of depression, lack of interest, deficient concentration, and a wish to be left alone. Nihilistic delusions, selfdepreciation (uncommon in depressed Iraqi patients), and suicidal tendencies were not seen. Insomnia of variable degree was complained of by most of the depressed patients but this did not follow a specific pattern. Appetite was not altered significantly.

\section{REPRESENTATIVE CASE HISTORIES}

CASE 1 S.F. is a 40 year old agricultural worker from South Iraq. He complained of numbness in his limbs for two weeks and was admitted to the neuropsychiatric unit in Medical City Hospital. The patient and his family consumed contaminated wheat for a period of nearly three months. His wife and five of their eight children were affected to various extents with symptoms appearing three to six weeks after cessation of the exposure.

Superficial sensation was diminished around the mouth and in both hands and feet. Position and vibration sensibilities were absent in the extremities, two-point threshold could not be measured, and stereognosis was impaired. The severe sensory defect was the only apparent neurological dysfunction. Blood levels for total and inorganic mercury were $2220 \mathrm{ng} / \mathrm{ml}$ and $73 \mathrm{ng} / \mathrm{ml}$ respectively.

On psychiatric assessment the patient was irritable, depressed, overwhelmed with melancholic thoughts, and obsessed to the most minor detail by various symptoms he had encountered. His low spirits were worse towards the evening, and he complained of insomnia and occasionally poor appetite.

CASE 2 R.S. is a 25 year old housewife from the middle regions of Iraq. She complained of unsteady gait and numbness (in her lower limbs) for one month and was admitted with three of her children to the paediatric unit in Medical City Hospital. The family had consumed contaminated wheat for two to three months and the symptoms appeared three to four weeks after cessation of the exposure.

On examination, the patient was ataxic but fully ambulant, with mild dysarthria and intention tremor. There was no objective loss in superficial or deep sensation; she was not examined for two-point threshold and stereognosis. Mercury blood levels were: total $2390 \mathrm{ng} / \mathrm{ml}$, inorganic $184 \mathrm{ng} / \mathrm{ml}$.

On psychiatric examination R.S. was depressed, tearful, and retarded. 'I feel bad, who will look after my children? I think it is the will of God that I should suffer; we have to accept His will'. The patient always stayed inside her room and tried hard not to leave it. Her sleep was often interrupted by nightmares. Overt psychotic phenomena were not elicited and cognitive functions were within the normal range.

\section{TABLE 1}

AVERAGE BLOOD LEVELS OF TOTAL AND INORGANIC MERCURY IN DEPRESSED AND NON-DEPRESSED PATIENTS

\begin{tabular}{lccc}
\hline Average values & $\begin{array}{c}\text { Whole group } \\
(36)^{*}\end{array}$ & $\begin{array}{c}\text { Depressed } \\
(26)^{*}\end{array}$ & $\begin{array}{c}\text { Non-depressed } \\
(10)^{*}\end{array}$ \\
\hline $\begin{array}{c}\text { Total mercury } \\
\mathrm{ng} / \mathrm{ml} \text { blood }\end{array}$ & 2118 & 2458 & 1234 \\
$\begin{array}{c}\text { Inorganic Hg } \\
\text { ng/ml blood }\end{array}$ & 146 & 175 & 72 \\
\hline
\end{tabular}

* Number of patients with known blood mercury levels.

In the depressed patients the average blood levels of total and inorganic mercury were higher than those in the whole group, and considerably higher than the corresponding values in the non-depressed patients (Table 1).

The difference between mean total mercury levels in the depressed and non-depressed patients was statistically significant $(P<0.05)$ (Table 2).

It is likely, therefore, that the mercury poisoning contributed significantly to the depression in our patients, but the environmental factors were 
TABLE 2

MEAN TOTAL MERCURY LEVELS IN DEPRESSED AND NON-DEPRESSED PATIENTS

\begin{tabular}{lcccc}
\hline Patients & No. & $\begin{array}{c}\text { Range of total Hg } \\
\text { in ng/ml blood }\end{array}$ & Mean & $\begin{array}{c}\text { Standard } \\
\text { deviation }\end{array}$ \\
\hline Depressed & 26 & $679-4200$ & 2458 & 1014.9 \\
Non-depressed & 10 & $320-2108$ & 1234 & 668.5 \\
\hline
\end{tabular}

also impressive. It is essential to stress the fact that these patients suffered physically, emotionally, and financially. Some of them had lost one or several members of their families, some had left near-relatives suffering, and still others had left their homes, farms, and live-stock unattended. The hospital, with its strict regulations and enclosed atmosphere, was very strange to their way of living. It is very difficult to assess the role of the various contributory factors in causing depression in the patients, and that of mercury poisoning in each case.

PSYCHOMOTOR DISTURBANCES Twenty-five of the depressed patients were retarded. Nine suffered from physical handicaps that contributed to their inactivity. Blindness, deafness, cerebellar involvement (manifested by nystagmus, dysarthria, and ataxia) and a clinical picture resembling polyneuropathy and leading to peripheral sensory impairment and quadriparesis, were encountered. It is worth mentioning that none of the patients in this study had static tremor.

Psychomotor activity was normal in 15 patients, including seven of the depressed group, and in three it was increased. There was no direct relationship between blood levels of mercury and the type of activity that was exhibited.

IRRITABILITY Irritability was viewed as excessive sensitivity to external stimuli, as well as exaggerated anger reactions. It was present in 19 patients (nine males and 10 females). There was no positive correlation with mercury levels, total or inorganic. There was, however, an increased preponderance of young patients: all those showing irritability as a sign of poisoning were below 30 years of age, except for one female patient aged 50 .

PERCEPTUAL ABNORMALITIES One patient, a 5 year old girl, exhibited what seemed to be auditory and visual hallucinations. She complained to her mother than she saw a 'woman' standing by the closet in her room, and that the 'woman' talked to her. This happened on two successive nights three weeks before hospital admission. The mother reported that her child was extremely frightened during these experiences. The patient's blood mercury levels were: total $1670 \mathrm{ng} / \mathrm{ml}$, and inorganic $39 \mathrm{ng} / \mathrm{ml}$. During her stay in hospital the symptoms were not repeated.

PHOBIC PHENOMENA Five patients, all female, suffered intense fear of death. Their blood mercury levels were variable. Each had lost one or more near relatives in the outbreak.

RECENT MEMORY This was impaired in sever patients, six of whom were also depressed an irritable. Total mercury blood levels were higher than $3000 \mathrm{ng} / \mathrm{ml}$ in the five patients imge whom estimations were done.

No patient exhibited delusions or thought dis order. Clinical assessment of orientation, remote memory, abstract thinking, and judgement showed that these functions were unaffected.

\section{TREATMENT AND PROGRESS}

Mercury-binding compounds were used to increase the clearance of mercury from blood and $\frac{9}{3}$ tissues. The following substances were administered to various groups of patients and each group included patients with different grades of clinical involvement: D-penicillamine; $\mathrm{N}$-acetyl-D, L-penicillamine; sodium 2, 3- 을 dimercaptopropanol; thiol resin (a polystyrenedivinylbenzene polymer containing benzythiol groups), and placebo.

The clearance of mercury as measured by repeated blood analysis was variable in different $\frac{D}{O}$ patients, with or without treatment (Magos, 1968; Bakir et al., 1973).

There was general clinical improvement in the $N$ mental state of most patients with psychiatric N manifestations. This was not significantly en- O 
hanced by mercury-binding compounds. It was noted, however, that patients with severe physical handicap continued to be depressed and irritable. There was also a remarkable improvement in patients with moderate or severe neurological abnormality. Patients bed-ridden because of severe ataxia became ambulant, others almost blind regained their visual acuity, and still others with peripheral sensory loss improved considerably. Again, the amelioration of the neurological deficit was not influenced by the mercury-binding substances.

\section{DISCUSSION}

Symptoms of depression and irritability occurred frequently in patients suffering from mercury poisoning in the outbreak in Iraq of 1972. Depressive symptoms were found to vary according to the blood levels of mercury (both organic and inorganic). The distressing consequences of the illness as well as the disruption of the patient's home and family life probably contributed as much as the direct toxic effect of the mercury on brain function.

These findings are compatible with earlier observations on the clinical effects of organic mercury poisoning in Minimata, Japan (Kurland et al., 1960) and in Iraq (Jalili and Abbasi, 1961; Damluji, 1962).

The chief culprit in the outbreaks in Minimata in 1953 and 1964, Iraq 1956 and 1960, Pakistan 1961, and Guatemala 1963 and 1964 was methylmercury. The symptoms included, in order of ascending severity, excessive weakness, fatigue, apathy, lack of interest, fits of rage, and depression (Eyl, 1971a).

On the other hand, psychiatric symptoms in the form of erethism, severe depression, and florid psychotic manifestations were not uncommonly reported in cases of industrial exposure to inorganic mercury (Johnstone and Miller, 1960; Koertge, 1965). Mercuric compounds used in the felt-hat industry gave rise to a considerable incidence of chronic mercurialism. The 'mad hatter' suffered from severe mental symptoms and was described, in the ' 30 s, as:

'easily upset, loses all joy of life and lives in constant fear of being dismissed. He has a sense of timidity and may lose self-control before strangers. Thus if visitors stop to watch him, he will sometimes throw down his tools and turn in anger towards the intruder. Drowsiness by day, depression, loss of memory and insomnia may occur and during the old days of the industry hallucinations, delusions and mania were seen more frequently in these patients' (Hunter, 1939).

Chronic mercury poisoning therefore seems to produce two different, though related, types of syndromes, the neurological and the psychiatric manifestations differing in extent and severity according to whether the organic or inorganic compound of mercury is involved.

Various factors could be considered in the aetiological differentiation of the two clinical syndromes: duration of exposure, amount of toxic substances ingested, the pathway of contamination, and the affinity of different tissues for organic and inorganic mercury compounds. We can assume that the sooner the highest tolerable concentration of mercury is reached in an organ the more readily signs and symptoms appear. This will depend upon the concentration to which that organ is exposed as well as the rate at which uptake and elimination occurs. This leads to several questions:

1. Is mercury deposited in the brain? The valuable experiments of Berlin and Ullberg (Berlin, 1963) with organic and inorganic mercurial compounds demonstrated the type of distribution and the variation in the concentration of mercury in different organs of the mouse. In the brain an especially high concentration was found in the cerebellar cortex, parts of the hypothalamus, and in the posterior part of the floor of the fourth ventricle. Histological and toxicological investigations on postmortem material obtained in the present epidemic showed that organic mercury is deposited in human brain tissue.

2. Has the brain tissue different affinity for organic and inorganic mercury compounds? In his studies on the metabolism of organic and inorganic mercury, Friberg (1959) found more mercury in the brain after injection of methylmercury than after inorganic mercury. The above facts correlate positively with clinical experience. Symptoms of methylmercury poisoning contrary to those of inorganic mercury intoxication involve chiefly the central nervous system (Eyl, 1971b).

3. Are organic and inorganic mercury com- 
pounds eliminated from the brain at different rates? In the experiments of Berlin and Ullberg (Berlin, 1963), a highly interesting point of direct clinical application is the difference in mercury elimination from the brain. Whereas elimination of inorganic mercury occurred in barely appreciable amounts, the quantity of organic (methyl) mercury eliminated had actually increased by about $30 \% 16$ days after administration. A further point of importance is that methylmercury is present in brain tissue of the rat mostly bound to proteins (Yoshino et al., 1966). It can be assumed, therefore, that differences in the metabolism of inorganic and organic mercury in the brain are responsible for the clinical psychiatric differences in the corresponding types of poisoning: the 'mad shaky hatter' as opposed to the 'ataxic depressed peasant'.

In conclusion, it is pertinent to ask whether the different effects of organic and inorganic mercury on the brain could be utilized for better understanding of its internal cellular organization. Could they provide a clue to the relationship of cellular proteins and enzyme systems to clinical psychiatric manifestations?

I am grateful to Professor F. Bakir and the Scientific Committee for permission to conduct this study and to use the data gathered on blood mercury levels, to Professor S. Damaluji for his advice, to my colleagues for allowing me to include their patients in this study, to $\mathrm{Mr}$ M. R. Greenwood for his help with mercury levels, to Dr A. Paton for his critical review of the manuscript, and to $\mathrm{Mr} \mathrm{A}$. El-Aloosy for carrying out the statistical analysis. I am most grateful to $\mathrm{Dr}$
H. Rustum for informations regarding the neurological state in some patients.

\section{REFERENCES}

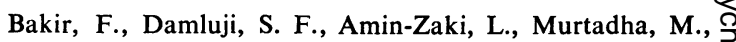
Khalidi, A., Al-Rawi, N. Y., Tikriti, S., Dhahir, H. I., Clarkson, T. W., Smith, J. C., and Doherty, R. A. (1973). Methylmercury poisoning in Iraq. An interuniversity . report. Science. 181, 230-241.

Berlin, M. (1963). On estimating threshold limits for mercury $\mathscr{G}$ in biological material. Acta Medica Scandinavica, 173, Suppl. 396.

Damluji, S. (1962). Mercurial poisoning with the fungicide $\overline{\bar{\omega}}$ Granosan M. Journal of the Faculty of Medicine (Baghdad), 4, 83-103.

Eyl, T. B. (1971a). Alkylmercury contamination of foods. ڤึ Journal of the American Medical Association, 215, 287-288.

Eyl, T. B. (1971b). Organic-mercury food poisoning. New. England Journal of Medicine, 284, 706-709.

Friberg, L. (1959). Studies on the metabolism of mercuric $\vec{w}$ chloride and methyl mercury dicyandiamide. Archives of Industrial Health, 20, 42-49.

Hunter, D. (1939). Industrial poisoning 5.-Mercury. In The British Encyclopaedia of Medical Practice, vol. 12, pp. $\omega$ 139-140. Butterworth: London.

Jalili, M. A., and Abbasi, A. H. (1961). Poisoning by eth: mercury toluene sulphonanilide. British Journal of Indus trial Medicine, 18, 303-308.

Johnstone, R. T., and Miller, S. E. (1960). Occupation Diseases and Industrial Medicine. Saunders: Philadelphis

Koertge, H. H. (1965). The hazard of mercury poisoning, don't be a mad hatter. Journal of the American Colleg Health Association, 13, 551-558.

Kurland, L. T., Faro, S. N., and Siedler, H. (1960). Minima disease. The outbreak of a neurologic disorder in Mint mata, Japan, and its relationship to the ingestion of seafood $\perp$ contaminated by mercuric compounds. World Neurology, 1, 370-395.

Magos, L. (1968). Effects of 2,3-dimercaptopropanol (BAL) on urinary excretion and brain content of mercury. British Journal of Industrial Medicine, 25, 152-154.

Yoshino, Y., Mozai, T., and Nakao, K. (1966). Biochemical changes in the brain in rats poisoned with an alkylmercury compound, with special reference to the inhibition of protein synthesis in brain cortex slices. Journal of Neurochemistry, 13, 1223-1230. 